\title{
Activation and Recruitment of Regulatory T Cells via Chemokine Receptor Activation in Trichinella spiralis- Infected Mice
}

\author{
Jeong-Bin Ahn ${ }^{1, \dagger}$, Shin Ae Kang ${ }^{1,2, \dagger}$, Dong-Hee Kim³, Hak Sun $\mathrm{Yu}^{1,2, *}$ \\ 'Department of Parasitology, School of Medicine, Pusan National University, Yangsan 50612, Korea; ${ }^{2}$ Immunoregulatory Therapeutics Group in \\ Brain Busan 21 Project, ${ }^{3}$ Department of Nursing, College of Nursing, Pusan National University, Yangsan 50612, Korea
}

\begin{abstract}
As most infections by the helminth parasite elicit the recruitment of $\mathrm{CD} 4^{+} \mathrm{CD} 25^{+} \mathrm{Foxp} 3^{+} \mathrm{T}\left(\mathrm{T}_{\text {reg }}\right)$ cells, many scientists have suggested that these cells could be used for the treatment of immune-mediated inflammation and associated diseases. In order to investigate the distribution and alteration of activated $T_{\text {reg }}$ cells, we compared the expression levels of $T_{\text {reg }}$ cell activation markers in the ileum and gastrocnemius tissues 1, 2, and 4 weeks after infection. The number of $\mathrm{T}_{\text {reg }}$ cells was monitored using GFP-coded Foxp3 transgenic mice. In mice at 1 week after Trichinella spiralis infection, the number of activated $T_{\text {reg }}$ cells was higher than in the control group. In mice at 2 weeks after infection, there was a significant increase in the number of cells expressing Foxp3 and CTLA-4 when compared to the control group and mice at 1 week after infection. At 4 weeks after infection, T. spiralis was easily identifiable in nurse cells in mouse muscles. In the intestine, the expression of Gzmb and Klrg1 decreased over time and that of Capg remained unchanged for the first and second week, then decreased in the 4th week. However, in the muscles, the expression of most chemokine genes was increased due to T. spiralis infection, in particular the expression levels of Gzmb, OX40, and CTLA-4 increased until week 4. In addition, increased gene expression of all chemokine receptors in muscle, CXCR3, CCR4, CCR5, CCR9, and CCR10, was observed up until the 4th week. In conclusion, various chemokine receptors showed increased expressions combined with recruitment of $\mathrm{T}_{\text {reg }}$ cells in the muscle tissue.
\end{abstract}

Key words: Trichinella spiralis, $\mathrm{CD} 4^{+} \mathrm{CD} 25^{+} \mathrm{F} 0 \mathrm{xp} 3^{+} \mathrm{T}$ cell, muscle phase, recruitment

\section{INTRODUCTION}

For 2 decades, the hygiene hypothesis - which proposes that the lack of early childhood exposure to infectious agents increases susceptibility to allergic diseases in later life - provided the conceptual framework for unravelling the mechanisms that could account for the increased incidence of allergic diseases [1]. Based on the "hygiene hypothesis", as people migrate to a more hygienic environment, there are less opportunities to encounter the sources of infection [2]. The difference in the occurrence of allergic and immune-mediated disorders between developing and developed countries may be attributed to the prevalence of helminth infections $[3,4]$. Childhood

- Received 2 January 2016, revised 5 March 2016, accepted 15 March 2016.

*Corresponding author (hsyu@pusan.ac.kr)

${ }^{\dagger}$ Jeong-Bin Ahn and Shin Ae Kang equally contributed in this study.

(c) 2016, Korean Society for Parasitology and Tropical Medicine

This is an Open Access article distributed under the terms of the Creative Commons Attribution Non-Commercial License (http://creativecommons.org/licenses/by-nc/3.0) which permits unrestricted non-commercial use, distribution, and reproduction in any medium, provided the original work is properly cited. microbial and helminth infection have been shown to decrease the risk of developing the inflammatory bowel disease (IBD) [5]. Infection may result in changes in the gut microbiota, which could lead to the changes in the complex immune response mechanisms, involving regulatory $\mathrm{T}\left(\mathrm{CD} 4^{+} \mathrm{CD} 25^{+}\right.$ Foxp3 ${ }^{+} \mathrm{T}, \mathrm{T}_{\mathrm{reg}}$ ) cells, toll-like receptor stimulation, etc. [6]. Almost all helminth infections elicit the recruitment of $\mathrm{T}_{\text {reg }}$ cells [7]. $\mathrm{T}_{\text {reg }}$ cells can inhibit the immune responses by directly killing cytotoxic cells through cell-to-cell contact, by inhibiting cytokine production of cytotoxic cells through IL-2 secretion, or by direct secretion of TGF- $\beta$ and IL-10 as immunomodulatory cytokines [8]. It has been proven that $\mathrm{T}_{\text {reg }}$ cells are useful in the treatment of immune-mediated inflammation, autoimmune and autoinflammatory disorders, allergies, acute and chronic infections, cancers, and metabolic inflammations [9].

Trichinella spiralis infection activates the Th2 response until the nurse cell formation but after the formation of nurse cells, the Th2 response to the infection declines. At the same time, $\mathrm{T}_{\text {reg }}$ cell numbers increase significantly in the spleen and in sev- 
eral lymph nodes [10]. This parasite infection or the products can ameliorate several immune disorders, allergic airway inflammation, intestinal inflammation, and experimental autoimmune encephalomyelitis in a mouse model by $\mathrm{T}_{\mathrm{reg}}$ cell recruitment and IL-10 ${ }^{+} \mathrm{T}$ cell activation [11-14]. Previous reports have suggested that $\mathrm{T}_{\text {reg }}$ cells are the most important cells in the amelioration of the allergic airway inflammation and intestinal inflammation [11-14]. Kang et al. [13] found that T. spiralis induced $\mathrm{T}_{\text {reg }}$ cells to migrate to the inflammation site and suppress the immune responses using adoptive transfer of $\mathrm{T}_{\text {reg }}$ cells.

However, the distribution of activated $\mathrm{T}_{\text {reg }}$ cells in specific tissues particularly the intestine and muscle tissues during the parasite life cycle is yet to be studied. In this study, we investigated the distribution and alteration of activated $\mathrm{T}_{\text {reg }}$ cell population by real-time PCR and immunohistochemistry analysis at each time point after T. spiralis infection.

\section{MATERIALS AND METHODS}

\section{Parasites}

T. spiralis strains (isolate code ISS623) were maintained in our laboratory through serial infection of rats. The parasites were isolated from the infected mice using dissection. Skin, fat, and internal organs were removed, and only the muscle and bones were used. The muscles and bones were cut into pieces, mixed with a digestive solution of $1 \%$ pepsin and $1 \%$ hydrochloride, and stirred continuously for $1 \mathrm{hr}$ at $37^{\circ} \mathrm{C}$. Then pepsin and hydrochloride were separated from the solution using a separating funnel, and the remains were washed with sterile PBS. After the wash, the muscle larvae of T. spiralis were collected.

\section{Preparation of samples}

GFP-tagged Foxp3 mice was purchased at Jackson Laboratory (Bar Harbor, Maine, USA) and kept in a pathogen-free facility at the Institute for Laboratory Animals of Pusan National University. Five-week-old mice were used. We designed 4 groups with 3 mice in each group; uninfected mice, 1-week-infected mice, 2-week-infected mice, and 4-week-infected mice. Each mouse was infected with 250 larvae of T. spiralis and was sacrificed after the designated infection time.

\section{Total RNA extraction and real-time PCR}

Total RNA was extracted from muscles and the intestine using $1 \mathrm{ml}$ of RiboEx (GeneAll, Seoul, Korea), $200 \mu \mathrm{l}$ chloroform
Table 1. Primer sequences for real-time PCR

\begin{tabular}{ll}
\hline Primer & Sequence \\
\hline GAPDH-for & 5'-TAC CCC CAA TGT GTC CGT C-3' \\
GAPDH-rev & 5'-AAG AGT GGG AGT TGC TGT TGA AG-3' \\
CTLA-4-for & 5'-GGA CGC AGA TIT ATG TCA TTG ATC-3' \\
CTLA-4-rev & 5'-CCA AGC TAA CTG CGA CAA GGA-3' \\
Klrg1- for & 5'-GGC TTG AGG AAC ATT GAT GG-3' \\
Klrg1-rev & 5'-TCA AGC TGT TGG TAA GAA TCC TC-3' \\
Capg- for & 5'-GCT GTG TGG CAA AAT CTA CAT C-3' \\
Capg-rev & 5'-GAT GAA GCC ATC AGC CAC TT-3' \\
Gzmb- for & 5'-GCT GCT CAC TGT GAA GGA AGT-3' \\
Gzmb-rev & 5'-TGG GGA ATG CAT TTT ACC AT-3' \\
GARP-for & 5'-TGA ATT CAT GAG CCA CCA GAT-3' \\
GARP-rev & 5'-AGC GGC CGC TCA GGC TTा GTA-3' \\
OX40-for & 5'-TAT GGT GAG CCG CTG TGA TC-3' \\
OX40-rev & 5'-ACA GTC AAG GGA GCC AGC AG-3' \\
CD62L-for & 5'-CAT TCC TGT AGC CGT CAT GG-3' \\
CD62L-rev & 5'-AGG AGG AGC TGT TGG TCA TG-3' \\
CXCR3-for & 5'-AGA ATC ATC CTG GTC TGA GAC AA-3' \\
CXCR3-rev & 5'-AAG ATA GGG CAT GGC AGC TA-3' \\
CCR4-for & 5'-ATC GTG CAC GCG GTA TTC TCC-3' \\
CCR4-rev & 5'-GAC GGG GTT AAG GCA GCA GTG A-3' \\
CCR5- for & 5'-GGA TT TCA AGG GTC AGT TC-3' \\
CCR5-rev & 5'-AAC CTT CTT TCT GAG ATC TGG-3' \\
CCR9- for & 5'-ATT GCA CAA GAG TGA AGA CC-3' \\
CCR9-rev & 5'-GTC AAC AGC CTG CAC TAC AA-3' \\
CCR10- for & 5'-CGG AGA AAC CCT TGT AGC CAG-3' \\
CCR10-rev & 5'-GGC CAA GAC TAG GCC ATT GCC-3' \\
\hline &
\end{tabular}

for, forward; rev, reverse

and $500 \mu$ isopropranol to remove the protein, DNA, and polysaccharides and to stabilize RNA. Extraction was carried out based on the protocol of the manufacturer. The CDNA was synthesized from the extracted RNA with MMLV reverse transcriptase (Promega, Madison, Wisconsin, USA) and oligo dT primer. Then, the CDNA of interest was amplified using gene specific primers (Table 1). The target genes were chemokine (C-X-C motif) receptor3 (CXCR3), chemokine (C-C motif) receptor4 (CCR), CCR5, CCR9, CCR10, killer cell lectin-like receptor subfamily G member 1(Klrg1), capping protein gelsolin-like (Capg), granzyme (Gzmb), glycoprotein A repetitions predominant (GARP), cytotoxic T-lymphocyte-associated protein 4 (CTLA-4), CD62 ligand (CD62L), and OX40 (CD134). The genes were amplified and measured by real-time PCR (Applied Biosystems 7500, Foster City, California, USA), and the relative gene transcription level was calculated based on the transcription level of the housekeeping gene GAPDH.

\section{Immunohistochemistry and confocal microscopy}

The muscles and intestines were dissected from each mouse, 
fixed with paraffin, sliced into thin slices, and mounted onto slides. Paraffin was then removed and the tissues were treated with an antigen retrieval solution of $0.1 \mathrm{M}$ citric acid, $0.1 \mathrm{M}$ sodium citrate, and $\mathrm{pH} 6.0$ for $20 \mathrm{~min}$. The slide was rinsed and treated with methanol $\left(0.3 \% \mathrm{H}_{2} \mathrm{O}_{2}\right)$ for 15 min in order to inhibit endogenous peroxidase activity. Before the incubation, the slides were placed in 1\% BSA for $1 \mathrm{hr}$ at room temperature. It was then incubated with hamster anti-mouse CTLA-4 (1:500; Santa Cruz Biotechnology, Santa Cruz, California, USA) for $1 \mathrm{hr}$ at $4^{\circ} \mathrm{C}$, was then washed several times with PBS before Alexa Fluor 594 goat anti-hamster IgG secondary antibody (1:500; Jackson Immuno Research Laboratories, West Grove, Pennsylvania, USA) was applied for $1 \mathrm{hr}$ at room temperature. After the application of CTLA-4 antibody and DAPI, the slides were washed and incubated for $2 \mathrm{~min}$. The prepared slides with their fluorescent signals were then observed under an inverted fluorescence microscope.

\section{Statistical analysis}

Means \pm SD were calculated, and significant differences were determined using the Student's $t$-test comparing all groups with the control group.

\section{RESULTS}

Alteration of $T_{\text {reg }}$ cell population in intestinal tissue during T. spiralis infection

In order to know how many $\mathrm{T}_{\text {reg }}$ cell were activated and where they migrate after infection, the $\mathrm{T}_{\text {reg }}$ cells were monitored in the intestine and muscle tissues after infection using GFP-tagged Foxp3 expressed mice. In the intestine, we easily located $\mathrm{T}_{\text {reg }}$ cells, not only in T. spiralis-infected mice, but also in uninfected mice (Fig. 1). In the uninfected mice (control), there was only a small number of activated $\mathrm{T}_{\text {reg }}$ cells (expressed both Foxp3 and CTLA-4). In mice at 1 week after T. spiralis infection, the number of activated $\mathrm{T}_{\text {reg }}$ cells increased in comparison to the control group. In the 2-week infected mice, the number of cells expressing Foxp3 and CTLA-4 was much greater than in the control and 1-week infected mice. However, 4-week infected mice showed a reduction in $\mathrm{T}_{\text {reg }}$ cell numbers to levels lower than that seen in 2-week infected mice (Fig. 1).

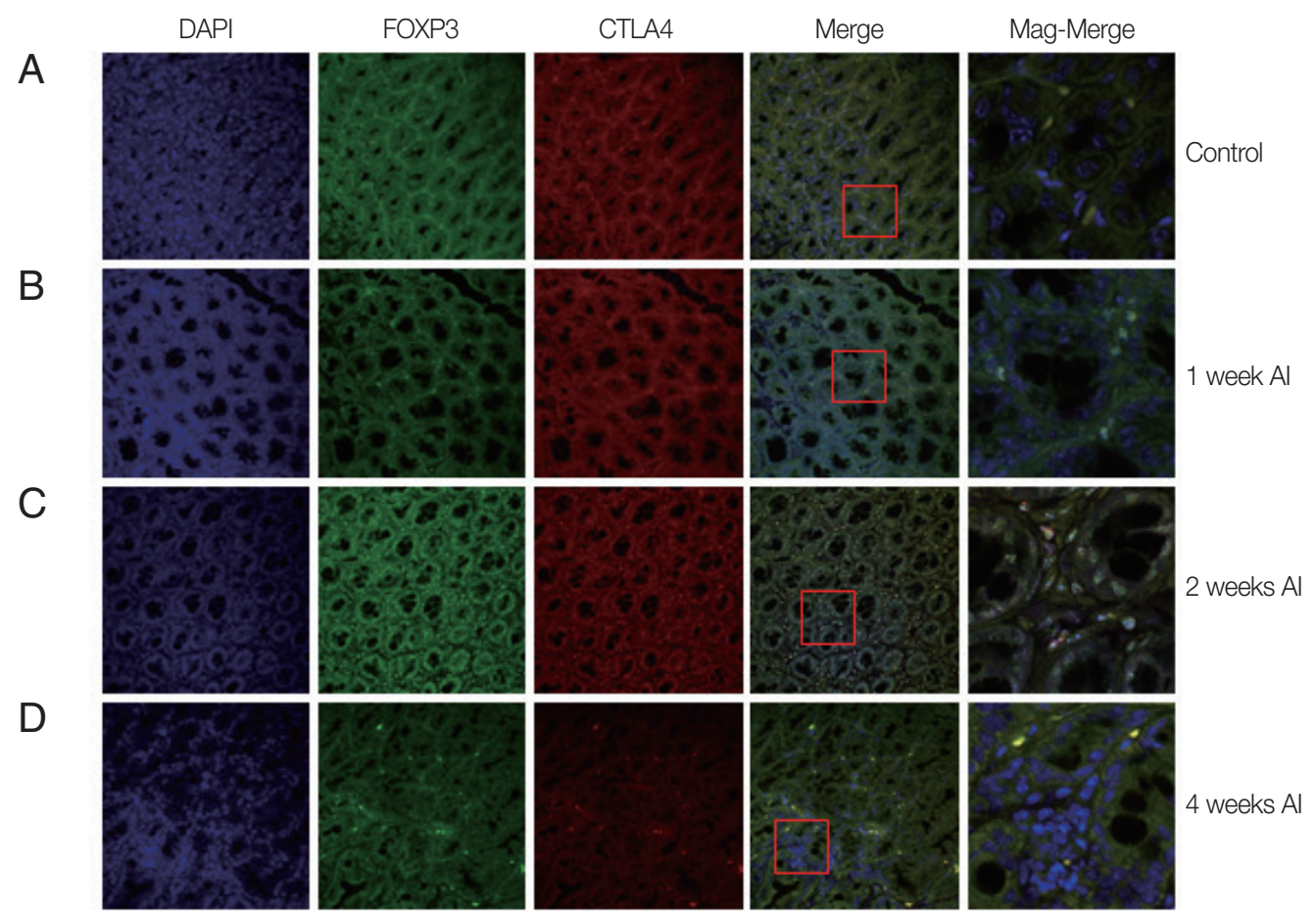

Fig. 1. Recruitment of $T_{\text {reg }}$ cells in the intestine after $T$. spiralis infection. Mice were infected with $T$. spiralis and sacrificed at $0,1,2$, and 4 weeks after infection. A fraction of the ileum tissue was dissected, and the sections were fixed and soaked in paraffin block. The thin section of the tissue was stained with DAPI and anti-CTLA-4 monoclonal antibody. The stained tissue was analyzed for cells expressing Foxp3, CTLA-4 using a confocal microscope. (A) Non-infected tissue. (B) 1 week after infection. (C) 2 weeks after infection. (D) 4 weeks after infection. 


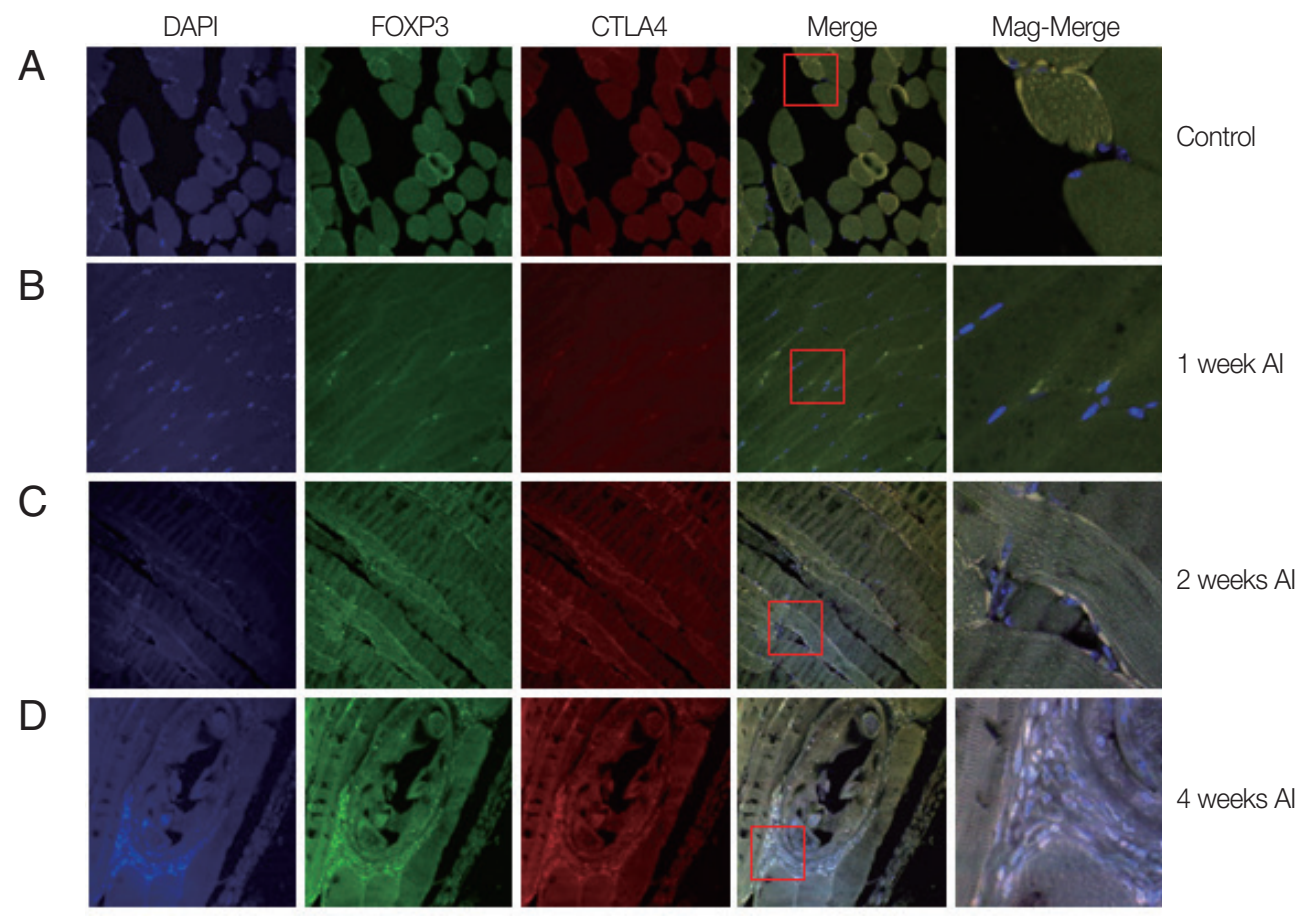

Fig. 2. Recruitment of $T_{\text {reg }}$ cells in muscles after $T$. spiralis infection. Mice were infected with $T$. spiralis and sacrificed at $0,1,2$, and 4 weeks after infection. The gastrocnemius tissue was dissected, and the tissues were fixed and soaked in paraffin block. The thin section of the tissue was stained with DAPI and anti-CTLA-4 monoclonal antibody. The stained tissue was analyzed for cells expressing Foxp3, CTLA-4 using a confocal microscope. (A) Non-infected tissue. (B) 1 week after infection. (C) 2 weeks after infection. (D) 4 weeks after infection.

\section{Recruitment of $T_{\text {reg }}$ cells around nurse cells}

Auto-fluorescence was observed for muscle tissues infected mice or un-infected mice. At 1 week after infection, the muscle tissue was quite similar to that of the control group. However, 2 weeks after infection, small-sized T. spiralis larvae were sparsely found in the muscle tissues (Fig. 2). The CTLA-4 expressed $\mathrm{T}_{\text {reg }}$ cells were recruited around T. spiralis larvae. At 4 weeks after infection, nurse cells containing T. spiralis were easily located in the muscle. A number of immune cells were recruited to the nurse cells and many expressed Foxp3 and CTLA-4 (Fig. 2).

Activation markers of $T_{\text {reg }}$ cells and gene expression levels of homing receptors in the intestine and muscle tissues during $T$. spiralis infection

The gene expression of activation marker of $\mathrm{T}_{\text {reg }}$ cell was evaluated to understand the functional features of $\mathrm{T}_{\text {reg }}$ cells recruited to the tissue. CTLA-4, Klrg1, Capg, GARP, Gzmb, OX40, and $C D 62 L$ were measured. In the intestine, the expression of Gzmb and Klrg1 was decreased over time, and Capg expression was unchanged for first and second week but decreased in the 4th week. GARP showed a significant and gradual increase until week 4. OX40 expression decreased 1 week after infection, then gradually increased until week 4 (Fig. 3A). However, in muscles, the gene expression levels of most chemokines were elevated due to T. spiralis infection, especially Gzmb, OX40, and CTLA-4 whose expression increased until week 4 . In addition, GARP, Klrg1 expression increased in first and second week but decreased 4 weeks after infection (Fig. 3B). The expression levels of chemokine receptors, CXCR3, CCR4, CCR5, CCR9, and CCR10, were measured to understand how the $\mathrm{T}_{\text {reg }}$ cells were recruited to the intestine and muscle after $T$. spiralis infection (Fig. 4). $\mathrm{T}_{\text {reg }}$ cell homing receptors guide $\mathrm{T}_{\text {reg }}$ cells to sites of inflammation quickly and accurately. The chemokine receptor expressed changes depending on the immunological setting and a change in chemokine receptor leads to a change in the distribution of $\mathrm{T}_{\mathrm{reg}}$ cells in the tissue. In the intestine, expression of CXCR3, CCR4, CCR5, CCR9 did not change significantly until week 4 but that of CCR10 had increased significantly at week 4 (Fig. 4A). However in muscle, all chemokine receptors in this study, CXCR3, CCR4, CCR5, CCR9, and CCR10, showed an increase in their expression levels until week 4 (Fig. 4B). 

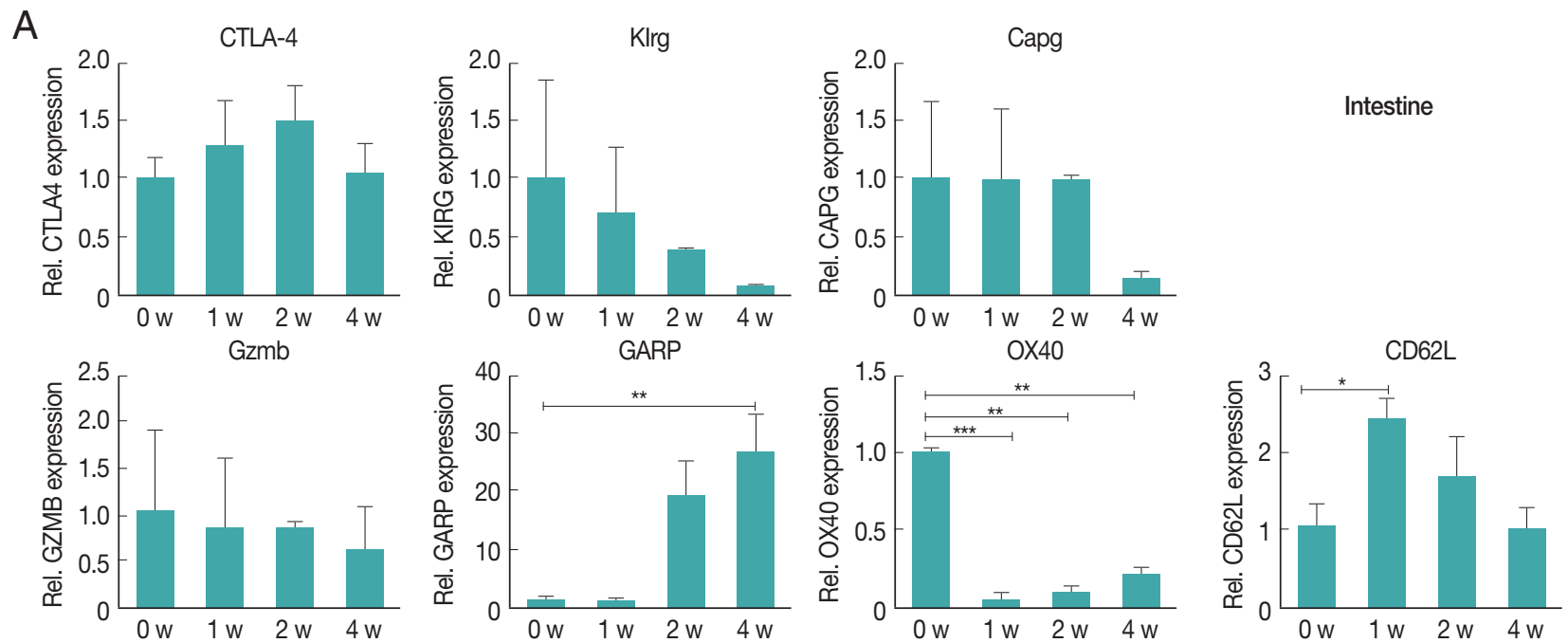

B
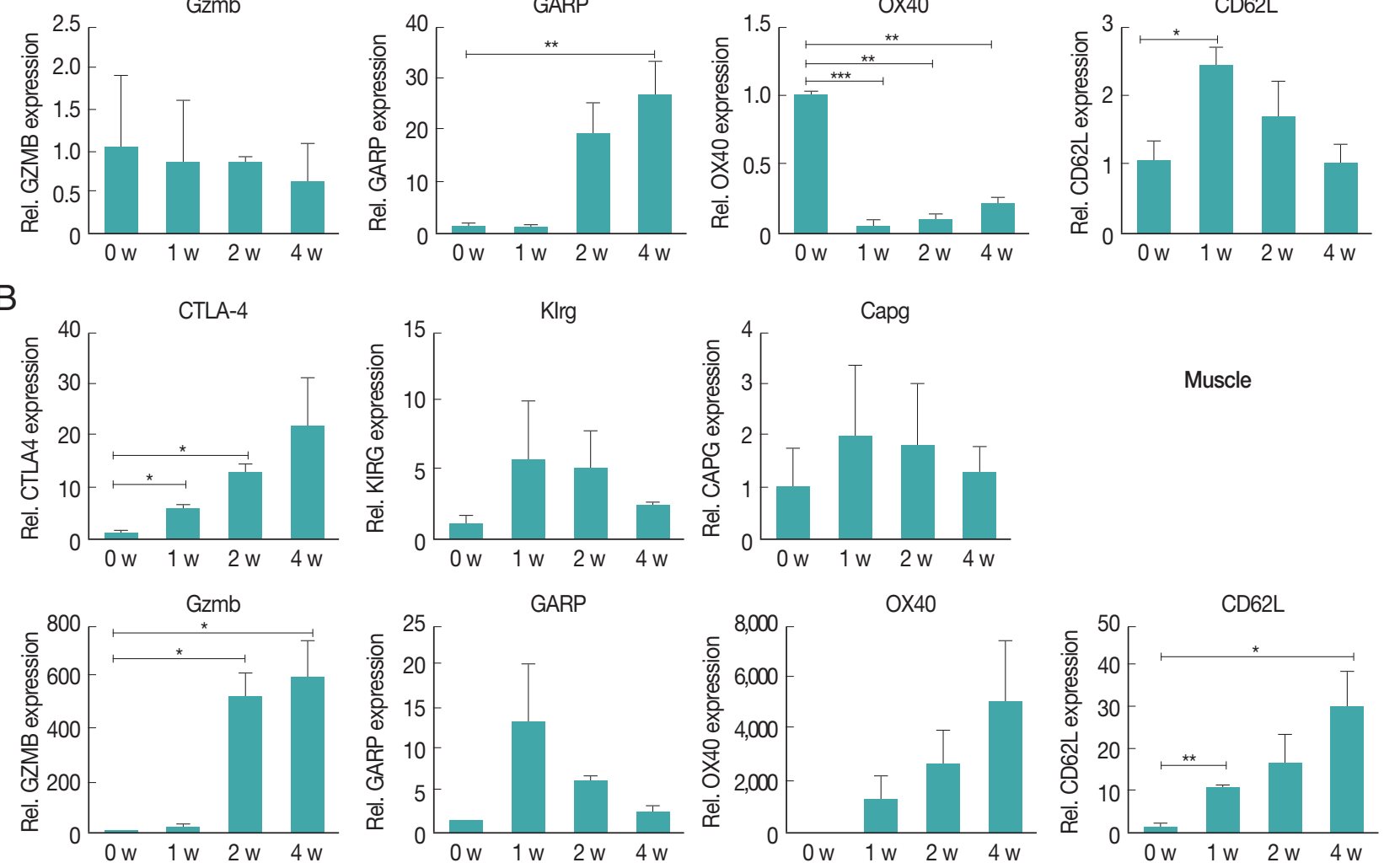

Fig. 3. Increased gene expression levels in $T_{\text {reg }}$ activation in the intestinal (A) and muscle (B) tissues after infection. Activation and functional marker gene expression levels of $T_{\text {reg }}$ cells were measured using real-time PCR. At 1,2, and 4 weeks after infection, the ileum and gastrocnemius tissues were isolated from mice. Total RNA was isolated from $1 \mathrm{~g}$ of the tissue. To determine activation and functional marker expression, the gene expression levels of CTLA-4, KIrg1, Capg, GARP, Gzmb, OX40, and CD62L were measured.

\section{DISCUSSION}

In this study, we observed the dynamic recruitment of $\mathrm{T}_{\text {reg }}$ cells during T. spiralis infection, especially around muscles and the small intestine, by confocal microscopy (Figs. 1, 2). In addition, although most $\mathrm{T}_{\text {reg }}$ cells were activated in both the intestine and muscle tissue, the patterns were quite different (Fig. 3). This might be caused by T. spiralis larva migration according to their life cycle. In the small intestine, T. spiralis invade the mucosal layer at 10-28 hr after infection and remain for 2-3 weeks [15]. The number of $\mathrm{T}_{\text {reg }}$ cells increased 1 and 2 weeks after infection, coinciding with the development stage of T. spiralis. At 4 weeks after infection, as T. spiralis reached the end of its life cycle, the number of $\mathrm{T}_{\text {reg }}$ cells decreased [10]. In muscles, the parasites started to invade at around 10 days and its nurse cells remained fully developed for 6 weeks after infection [15]. Thus, the number of the activated $\mathrm{T}_{\text {reg }}$ cells did not change in muscle tissue for 0-1 weeks after infection, after that it rapidly increased around the parasite until the 4th week of infection when the nurse cells were fully developed (Fig. 3).

Why do $\mathrm{T}_{\text {reg }}$ cells increase during invasion and development of T. spiralis? When infected with T. spiralis, the immune system activates the Th2 pathway which induces an inflammatory response against the intruder [10]. However, too strong an im- 
A
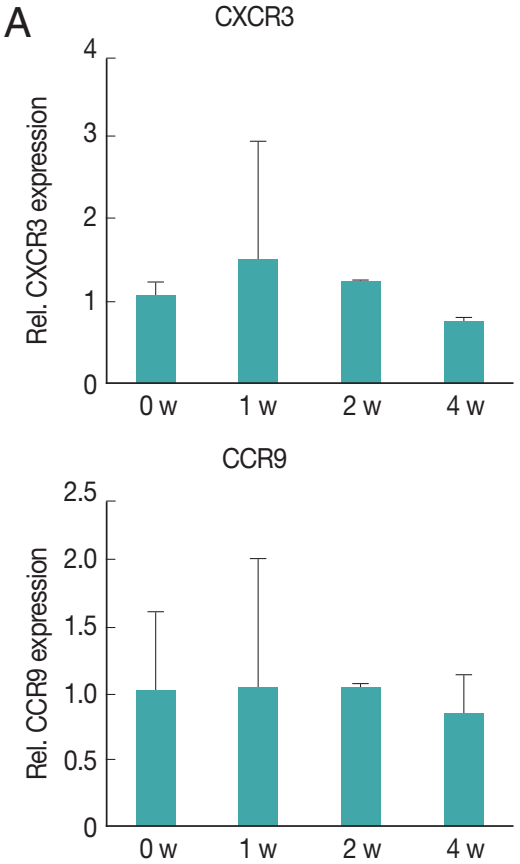

B
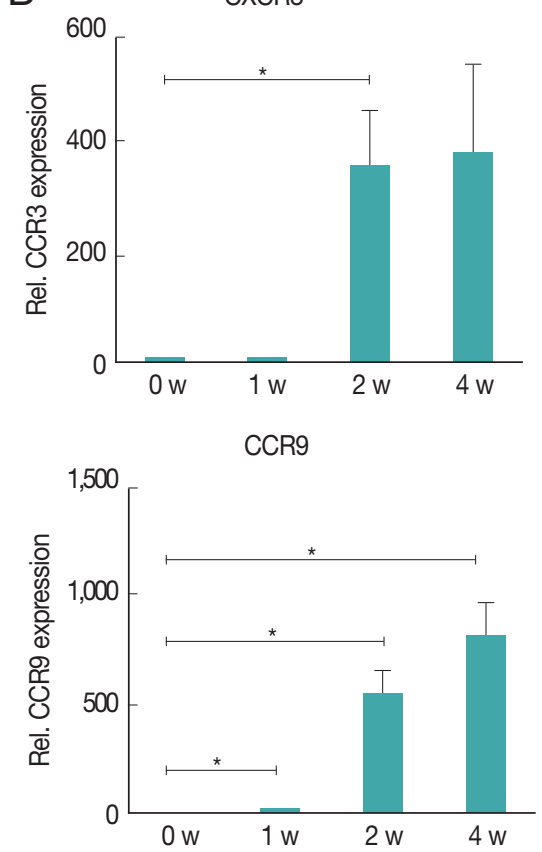

CCR4
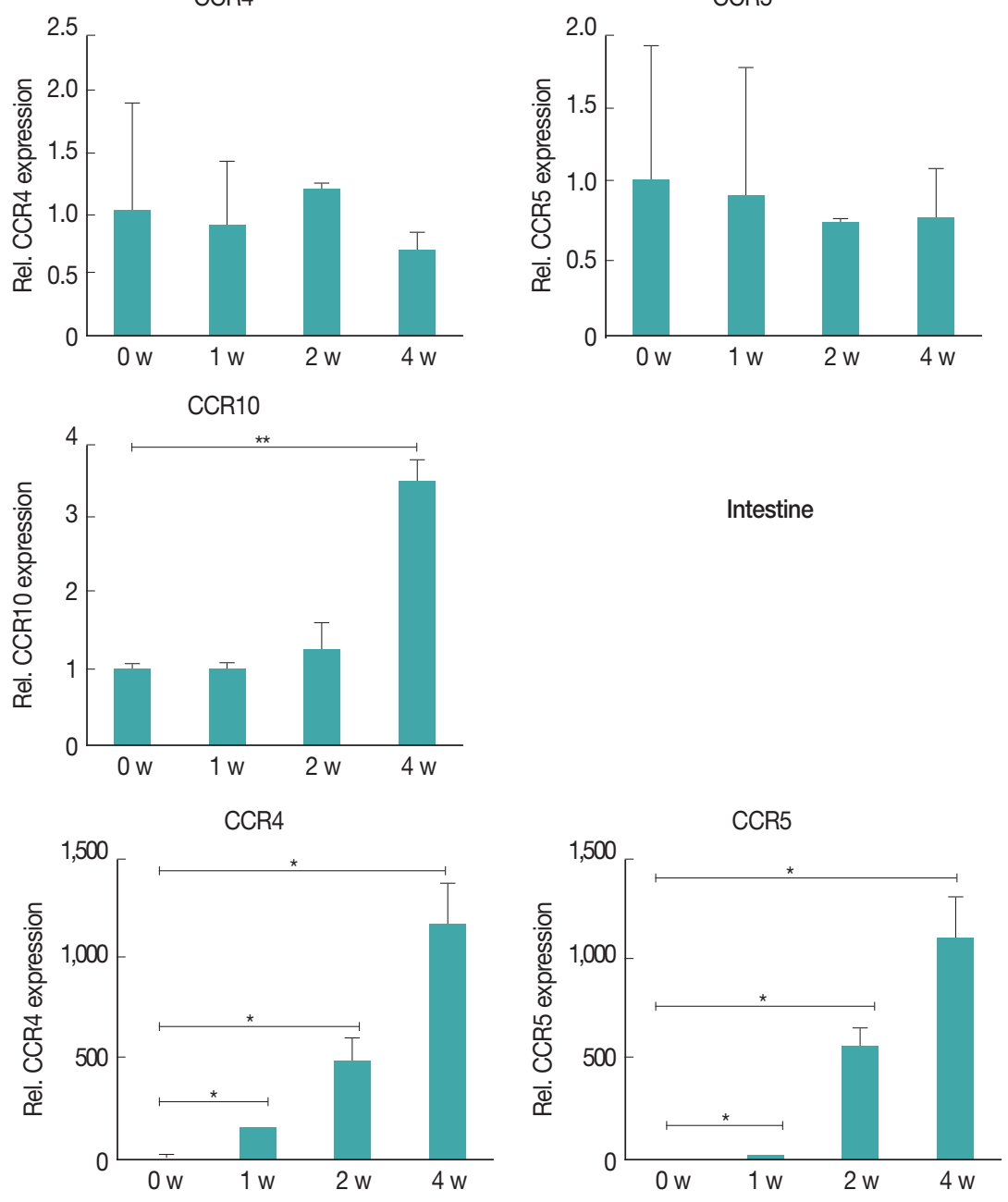

Muscle

Fig. 4. Chemokine receptors in the muscle tissue showed higher levels of increased gene expression compared to receptors in the intestine after infection. Gene expression levels of chemokine receptors were measured using real-time PCR. At 1, 2, and 4 weeks after infection, the intestinal $(\mathrm{A})$ and gastrocnemius (B) tissues were isolated from mice. Total RNA was isolated from $1 \mathrm{~g}$ of the tissue. CXCR3, CCR4, CCR5, CCR9, and CCR10 gene levels were measured.

mune reaction cannot only kill the foreign substance but also the host's own tissues. Thus, the immune response is regulated by $\mathrm{T}_{\text {reg }}$ cells that are activated when there is an excessively large or long immune response. Some parasite infections induce $\mathrm{T}_{\text {reg }}$ cells, and these $\mathrm{T}_{\text {reg }}$ cells activate specific genes, such as those encoding Foxp3, CTLA-4, CD103, GITR, OX40, Gzmb, Klrg1, secretory leukocyte peptidase inhibitor (Slpi), fatty acid-binding protein 5 (Fabp5), nuclear factor, IL-3 regulated (Nfil3), suppressor of cytokine signaling 2 (Socs2) and G protein-coupled receptor 177 (Gpr177) [16-20]. In this study, we also ob- 
served highly expression of several genes for $\mathrm{T}_{\text {reg }}$ cell activations [GARP and CD62L in intestine; CTLA-4, Gzmb, and CD62L in muscle tissue] (Fig. 3). The CTLA-4 activates the transmission of immunosuppressive signals on $\mathrm{T}$ effector cells by interacting the T effector ligands CD80 and CD86 [21,22]. GARP, which are expressed on the surface of activated $\mathrm{T}_{\text {reg }}$ cells, suppresses IL-2 and IFN- $\gamma$ production and the differentiation and proliferation of naïve $\mathrm{T}$ cells into $\mathrm{T}$ effector cells, leading to the differentiation of naive $\mathrm{T}$ cells into induced $\mathrm{T}_{\text {reg }}$ cells $[23,24]$. Blocking OX40 on $\mathrm{T}_{\text {reg }}$ cells inhibits the cells' ability to suppress and restores effecter T-cell proliferation [25]. Gzmb is released by activated $\mathrm{T}_{\text {reg }}$ cells, and it functionally induces apoptosis of naive $\mathrm{B}$ cells [26]. CD62L high-expressed $\mathrm{T}_{\text {reg }}$ cells have a higher immunosuppressive capacity than CD62 low expressed $\mathrm{T}_{\text {reg }}$ cells [27]. Therefore, T. spiralis could activate $\mathrm{T}_{\text {reg }}$ cell to suppress host Th2 immune response to them.

Activation of $\mathrm{T}_{\text {reg }}$ cell as well as How $\mathrm{T}_{\text {reg }}$ cells reach the target organ is also important. Studies about the localization of $\mathrm{T}_{\text {reg }}$ cells into specific sites reveal that the migratory behavior of $\mathrm{T}_{\text {reg }}$ cells is crucial for its regulatory role [28]. Chemokine receptors that are expressed on the surface of the cells play a major role in $\mathrm{T}_{\text {reg }}$ migration. Both the expression level and pattern of chemokine receptors determine the destination of a $\mathrm{T}_{\text {reg }}$ cell. The result from the intestines show that only CCR10 expression increased significantly during the 4 weeks of infection (Fig. 4). The expression levels of other chemokine receptors, CXCR3, CCR4, CCR5, and CCR9 remained mostly unchanged (Fig. 4). CCR10 is a chemokine receptor that homes to epithelial cells and interacts with CCL27 and CCL28 ligands [6]. Although CCL27 is mainly expressed in keratinocytes [29], CCL28 is widely expressed in various mucosal tissues [30-32]. Eksteen et al. [30] isolated a subset of CCR10-expressing $\mathrm{T}_{\text {reg }}$ cells from a chronically inflamed human liver. Exposure of CCR $10^{+} \mathrm{T}_{\text {reg }}$ cells to CCL28 in vitro stimulated migration and adhesion to mucosal addressin cell adhesion molecule-1 (MAdCAM-1) and vascular cell adhesion protein-1 (VCAM-1) [30]. During the 4 weeks of infection, T. spiralis stayed in the mucosa layer for the entirety of its 4-week life span (Fig. 1). The increased expression of CCR10 in $\mathrm{T}_{\text {reg }}$ cells leads to the localization of $\mathrm{T}_{\text {reg }}$ cells into mucosal tissue of small intestine and thus, the regulation of the inflammatory response caused by T. spiralis. The result from muscle tissues show a significant increase in the level of all the chemokine receptors, CXCR3, CCR4, CCR5, CCR9, and CCR10 (about 400 fold - about 1,500 fold than control) during the 4 weeks of infection (Fig. 4). The increase in the expression of the CCR4 gene was the most remarkable $(>1,500$ fold than control). CCR4 is expressed on the majority of $T_{\text {reg }}$ cells, especially on effector $T_{\text {reg }}$ cells [33]. In vivo administration of anti-CCR4 mAb markedly reduced the effect $\mathrm{T}_{\text {reg }}$ cells population in an adult T-cell leukemia-lymphoma patient [34]. In addition, CCR4 interacts with CCL22 expressed on the surface of matured dendritic cells (DCs) [35]. Therefore, CCR4 expression might be closely related to $\mathrm{T}_{\text {reg }}$ cell activation. CCR4 upregulation in $\mathrm{T}_{\text {reg }}$ cells can home the cell to the lymph nodes for efficient activation [34,35].

Along with CCR4, CCR5, CXCR3, and CCR9 have $\mathrm{T}_{\text {reg }}$ cell related immunological effects on inflammation. CCR5 prevents uncontrolled post-infarction inflammation and protects from adverse remodeling by recruiting suppressive mononuclear cells [36]. Moreover, enhanced inflammation in the absence of CCR5 was associated with impaired recruitment of $\mathrm{T}_{\text {reg }}$ cells [36]. The CCR5 ${ }^{+} \mathrm{T}_{\text {reg }}$ cell subset exhibited increased IL10 expression, reflecting potent anti-inflammatory activity [36]. The chemokine CXCR3 is expressed in the liver, lung and intestine and it reacts reacted with Th1-associated chemokines CXCL9, CXCL10, and CXCL11 [37]. Therefore, when Th1-associated chemokine-expression is high in an organ, it might suppress $\mathrm{CXCR}^{+} \mathrm{T}_{\text {reg }}$ cells. In trichinellosis, Th1 cytokine expression was highly increased temporarily, but this elevation was suppressed by $\mathrm{T}_{\text {reg }}$ cell activation and recruitment [10]. Interestingly, CCR9 (gut homing receptor) expression did not increase in the intestine tissue but increased in the muscle tissue during T. spiralis infection. CCR9, a gut-trophic chemokine receptor expressed by lymphocytes and dendritic cells, has been implicated in the regulation of IBD as it mediates the recruitment of $\mathrm{T}$ cells to site of inflammation $[38,39]$. Further studies are need to determine the CCR9-related mechanisms in trichinellosis.

In conclusion, we found higher levels of $\mathrm{T}_{\text {reg }}$ cell activation markers and recruitment in muscle tissue than in intestinal tissue. The expression of various chemokine receptors (most of them were closely related with $\mathrm{T}_{\text {reg }}$ cell recruitment) increased in the muscle tissue. These chemokine receptors might help in the migration and activation of $\mathrm{T}_{\text {reg }}$ cells and thus might be one of host's immunomodulation strategies in response to $T$. spiralis infection.

\section{ACKNOWLEDGMENT}

This research was supported by Basic Science Research Pro- 
gram through the National Research Foundation of Korea (NRF) funded by the Ministry of Science, ICT \& Future Planning, the Republic of Korea (NRF-2013R1A1A2060219).

\section{CONFLICT OF INTEREST}

We have no conflict of interest related to this work.

\section{REFERENCES}

1. Julia V, Macia L, Dombrowicz D. The impact of diet on asthma and allergic diseases. Nat Rev Immunol 2015; 15: 308-322.

2. Loke P, Lim YA. Helminths and the microbiota: parts of the hygiene hypothesis. Parasite Immunol 2015; 37: 314-323.

3. Flohr C, Quinnell RJ, Britton J. Do helminth parasites protect against atopy and allergic disease? Clin Exp Allergy 2009; 39: 2032.

4. Fogarty AW. What have studies of non-industrialized countries told us about the cause of allergic disease? Clin Exp Allergy 2015; 45: 87-93.

5. Zaph C, Cooper PJ, Harris NL. Mucosal immune responses following intestinal nematode infection. Parasite Immunol 2014; 36: 439-452.

6. Xiong N, Fu Y, Hu S, Xia M, Yang J. CCR10 and its ligands in regulation of epithelial immunity and diseases. Protein Cell 2012; 3: 571-580

7. Taylor MD, van der Werf N, Maizels RM. T cells in helminth infection: the regulators and the regulated. Trends Immunol 2012; 33: 181-189.

8. Peterson RA. Regulatory T-cells: diverse phenotypes integral to immune homeostasis and suppression. Toxicol Pathol 2012; 40: 186-204.

9. Askenasy N, Kaminitz A, Yarkoni S. Mechanisms of T regulatory cell function. Autoimmun Rev 2008; 7: 370-375.

10. Kang SA, Cho MK, Park MK, Kim DH, Hong YC, Lee YS, Cha HJ, Ock MS, Yu HS. Alteration of helper T-cell related cytokine production in splenocytes during Trichinella spiralis infection. Vet Parasitol 2012; 186: 319-327.

11. Park HK, Cho MK, Choi SH, Kim YS, Yu HS. Trichinella spiralis: infection reduces airway allergic inflammation in mice. Exp Parasitol 2011; 127: 539-544.

12. Cho MK, Park MK, Kang SA, Choi SH, Ahn SC, Yu HS. Trichinella spiralis infection suppressed gut inflammation with $\mathrm{CD} 4^{+} \mathrm{CD} 25^{+}$ Foxp3 ${ }^{+}$T cell recruitment. Korean J Parasitol 2012; 50: 385-390.

13. Kang SA, Park MK, Cho MK, Park SK, Jang MS, Yang BG, Jang $\mathrm{MH}$, Kim DH, Yu HS. Parasitic nematode-induced CD4+Foxp3 ${ }^{+}$ T cells can ameliorate allergic airway inflammation. PLoS Negl Trop Dis 2014; 8: e3410.

14. Radovic I, Gruden-Movsesijan A, Ilic N, Cvetkovic J, Mojsilovic S, Devic M, Sofronic-Milosavljevic L. Immunomodulatory effects of Trichinella spiralis-derived excretory-secretory antigens. Immu- nol Res 2015; 61: 312-325.

15. Campbell WC. Trichinella and trichinosis. New York, USA. Plenum Press. 1983, p 581.

16. Shevach EM. Mechanisms of Foxp $3^{+} \mathrm{T}$ regulatory cell-mediated suppression. Immunity 2009; 30: 636-645.

17. Ephrem A, Epstein AL, Stephens GL, Thornton AM, Glass D, Shevach EM. Modulation of $\mathrm{T}_{\text {reg }}$ cells/T effector function by GITR signaling is context-dependent. Eur J Immunol 2013; 43: 24212429.

18. Xiao X, Gong W, Demirci G, Liu W, Spoerl S, Chu X, Bishop DK, Turka LA, Li XC. New insights on OX40 in the control of T cell immunity and immune tolerance in vivo. J Immunol 2012; 188: 892-901.

19. Loebbermann J, Thornton H, Durant L, Sparwasser T, Webster KE, Sprent J, Culley FJ, Johansson C, Openshaw PJ. Regulatory T cells expressing granzyme B play a critical role in controlling lung inflammation during acute viral infection. Mucosal Immunol 2012; 5: 161-172.

20. Tai XG, Van Laethem F, Pobezinsky L, Guinter T, Sharrow SO, Adams A, Granger L, Kruhlak M, Lindsten T, Thompson CB, Feigenbaum L, Singer A. Basis of CTLA-4 function in regulatory and conventional CD4+ T cells. Blood 2012; 119: 5155-5163.

21. Velavan TP, Ojurongbe O. Regulatory T cells and parasites. J Biomed Biotechnol 2011; 2011: 520940.

22. Buchbinder EI, Desai A. CTLA-4 and PD-1 pathways: similarities, differences, and implications of their inhibition. Am J Clin Oncol 2016; 39: 98-106.

23. Hahn SA, Stahl HF, Becker C, Correll A, Schneider FJ, Tuettenberg A, Jonuleit H. Soluble GARP has potent antiinflammatory and immunomodulatory impact on human CD4+ T cells. Blood 2013; 122: 1182-1191.

24. Sun L, Yi S, O'Connell PJ. Foxp3 regulates human natural $\mathrm{CD} 4{ }^{+} \mathrm{CD} 25^{+}$regulatory T-cell-mediated suppression of xenogeneic response. Xenotransplantation 2010; 17: 121-130.

25. Mahmud SA, Manlove LS, Schmitz HM, Xing Y, Wang Y, Owen DL, Schenkel JM, Boomer JS, Green JM, Yagita H, Chi H, Hogquist KA, Farrar MA. Costimulation via the tumor-necrosis factor receptor superfamily couples TCR signal strength to the thymic differentiation of regulatory T cells. Nat Immunol 2014; 15: 473-481.

26. Shevach EM, DiPaolo RA, Andersson J, Zhao DM, Stephens GL, Thornton AM. The lifestyle of naturally occurring CD4 ${ }^{+} \mathrm{CD} 25$ Foxp $3^{+}$regulatory T cells. Immunol Rev 2006; 212: 60-73.

27. Lange C, Scholl M, Melms A, Bischof F. CD62L(high) Treg cells with superior immunosuppressive properties accumulate within the CNS during remissions of EAE. Brain Behav Immun 2011; 25: $120-126$

28. Bromley SK, Mempel TR, Luster AD. Orchestrating the orchestrators: chemokines in control of T cell traffic. Nat Immunol 2008; 9: 970-980.

29. Homey B, Alenius H, Müller A, Soto H, Bowman EP, Yuan W, McEvoy L, Lauerma AI, Assmann T, Bünemann E, Lehto M, Wolff H, Yen D, Marxhausen H, To W, Sedgwick J, Ruzicka T, 
Lehmann P, Zlotnik A. CCL27-CCR10 interactions regulate T cell-mediated skin inflammation. Nat Med 2002; 8: 157-165.

30. Eksteen B, Miles A, Curbishley SM, Tselepis C, Grant AJ, Walker LS, Adams DH. Epithelial inflammation is associated with CCL28 production and the recruitment of regulatory T cells expressing CCR10. J Immunol 2006; 177: 593-603.

31. English K, Brady C, Corcoran P, Cassidy JP, Mahon BP. Inflammation of the respiratory tract is associated with CCL28 and CCR10 expression in a murine model of allergic asthma. Immunol Lett 2006; 103: 92-100.

32. Castelletti E, Lo Caputo S, Kuhn L, Borelli M, Gajardo J, Sinkala M, Trabattoni D, Kankasa C, Lauri E, Clivio A, Piacentini L, Bray DH, Aldrovandi GM, Thea DM, Veas F, Nebuloni M, Mazzotta F, Clerici M. The mucosae-associated epithelial chemokine (MEC/ CCL28) modulates immunity in HIV infection. PLoS One 2007; 2: e969.

33. Wang Z, Pratts SG, Zhang H, Spencer PJ, Yu R, Tonsho M, Shah JA, Tanabe T, Powell HR, Huang CA, Madsen JC, Sachs DH, Wang $\mathrm{Z}$. $\mathrm{T}_{\text {reg }}$ depletion in non-human primates using a novel diphtheria toxin-based anti-human CCR4 immunotoxin. Mol Oncol 2016; 10: 553-565.

34. Sugiyama D, Nishikawa H, Maeda Y, Nishioka M, Tanemura A, Katayama I, Ezoe S, Kanakura Y, Sato E, Fukumori Y, Karbach J, Jäger E, Sakaguchi S. Anti-CCR4 mAb selectively depletes effector-type FoxP3 ${ }^{+} \mathrm{CD}^{+}$regulatory $\mathrm{T}$ cells, evoking antitumor im- mune responses in humans. Proc Natl Acad Sci USA 2013; 110: 17945-17950.

35. Kurose K, Ohue Y, Sato E, Yamauchi A, Eikawa S, Isobe M, Nishio Y, Uenaka A, Oka M, Nakayama E. Increase in activated $\mathrm{T}_{\text {reg }}$ in TIL in lung cancer and in vitro depletion of $\mathrm{T}_{\text {reg }}$ by ADCC using an antihuman CCR4 mAb (KM2760). J Thorac Oncol 2015; 10: 74-83.

36. Dobaczewski M, Xia Y, Bujak M, Gonzalez-Quesada C, Frangogiannis NG. CCR5 signaling suppresses inflammation and reduces adverse remodeling of the infarcted heart, mediating recruitment of regulatory T cells. Am J Pathol 2010; 176: 21772187.

37. Hasegawa H, Inoue A, Kohno M, Lei J, Miyazaki T, Yoshie O, Nose M, Yasukawa M. Therapeutic effect of CXCR3-expressing regulatory $\mathrm{T}$ cells on liver, lung and intestinal damages in a murine acute GVHD model. Gene Ther 2008; 15: 171-182.

38. Evans-Marin HL, Cao AT, Yao S, Chen F, He C, Liu H, Wu W, Gonzalez MG, Dann SM, Cong Y. Unexpected regulatory role of CCR9 in regulatory T cell development. PLoS One 2015; 10: e0134100.

39. Wermers JD, McNamee EN, Wurbel MA, Jedlicka P, RiveraNieves J. The chemokine receptor CCR9 is required for the Tcell-mediated regulation of chronic ileitis in mice. Gastroenterology 2011; 140: 1526-1535.e3. 